\title{
US treasury seeks bright ideas to beat bogus dollars
}

\section{WASHINGTON DC}

Threatened by cheap, high-quality laser printers and other technologies producing counterfeit currency, the US Department of the Treasury has asked leading scientists to come up with ways to defeat phoney bills.

The National Academy of Sciences applied itself to the subject in 1993, when it urged the treasury to use features such as watermarks and colour-changing ink. These were duly incorporated in bills, but are now being faked in an increasing number of counterfeits.

Last year, \$43 million in counterfeit money was removed from circulation in the United States. "Counterfeiters are getting awfully good, especially with all the digital technology," says Goutam Gupta, head of technical support at the treasury's Bureau of Engraving and Printing.

Now an academy panel is pondering how to fight back. The newly appointed group includes experts in biomaterials, optics and

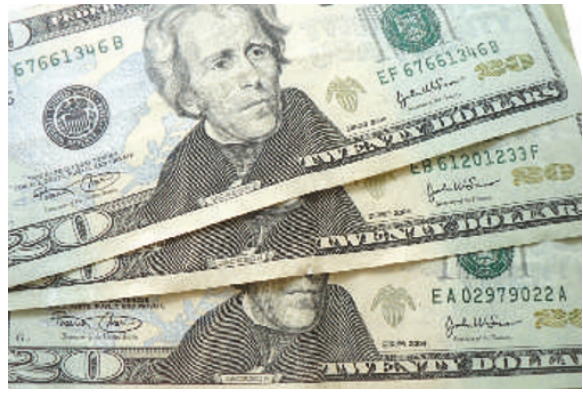

Face lift: dollars may soon look quite different.

neuroscience, and may explore avenues such as nanotechnology. Any new element on bills would have to be difficult to simulate, but cheap to mass-produce and easy to recognize.

For example, the euro quickly became a target for counterfeiters, because it is so widely used. But with features such as holograms, iridescence, watermarks and a security thread, it is faked less than the currencies it replaced.
"We want something that will attract a person's eye," says Lenora Clarke of the bureau, which pumps out almost $\$ 700$ million each day.

Not all cashiers look carefully enough at bills to notice something as subtle as the absence of a security strip, says Lisa DiNunzio, programme manager within the bureau's office of security technology. The most useful feature, according to bank tellers, is the feel of the bill. Unlike more usual wood-based paper, dollars are made of cotton and linen.

But counterfeiters can get around this by bleaching off the markings on another kind or denomination of currency. The US Secret Service has found $\$ 100$ bills printed on bleachedout Iraqi dinars, for example, with the original watermark of a horse faintly visible over Ben Franklin's shoulder.

The panel expects to finish its work within two years, but hopes to issue interim recommendations by February 2006.

Emma Marris 